\title{
Driven to distraction, doctors and patients are renegotiating virtual visits
}

\author{
n Cite as: CMAJ 2020 November 2;192:E1372-3. doi: 10.1503/cmaj.1095903
}

Posted on cmajnews.com on October 16, 2020

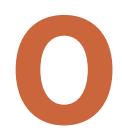

ttawa bariatric physician Dr. Yoni Freedhoff realized during a video appointment that his patient was driving. He asked the patient to pull over, but soon it became clear they were back on the road.

"I politely hung up, saying, 'This is not safe. I am sorry I cannot continue with this consult," "Freedhoff recounts. "I don't think there's any room for debating that a video conference is a safe thing to do while driving."

Patients ought to respect physicians' time, and vice versa, he says. "As for distractions, I don't know how you force someone to pay attention."

Modern medical practice is full of distractions. But until recently, most have come from the physician side of the doctor-patient relationship, with one recent paper citing the "endless clicks within the electronic medical record, fast-paced office hours with shortened appointment slots... and the constant ringing of our cellphones."

Now, the sudden shift to more virtual care consults during the pandemic is forcing clinicians to renegotiate the rules of engagement with their patients.

When Freedhoff told his story on Twitter, other clinicians shared similar experiences and concerns about patients multitasking during virtual visits. Some patients were sympathetic, while others took issue with the thread.

Dr. Jason Lee, an immunology and allergy specialist in Toronto, says it's up to clinicians to make their expectations clear. "Some people seem to be unaware that this is an appointment, just like in person. They have no problem putting me on hold repeatedly. I will call them

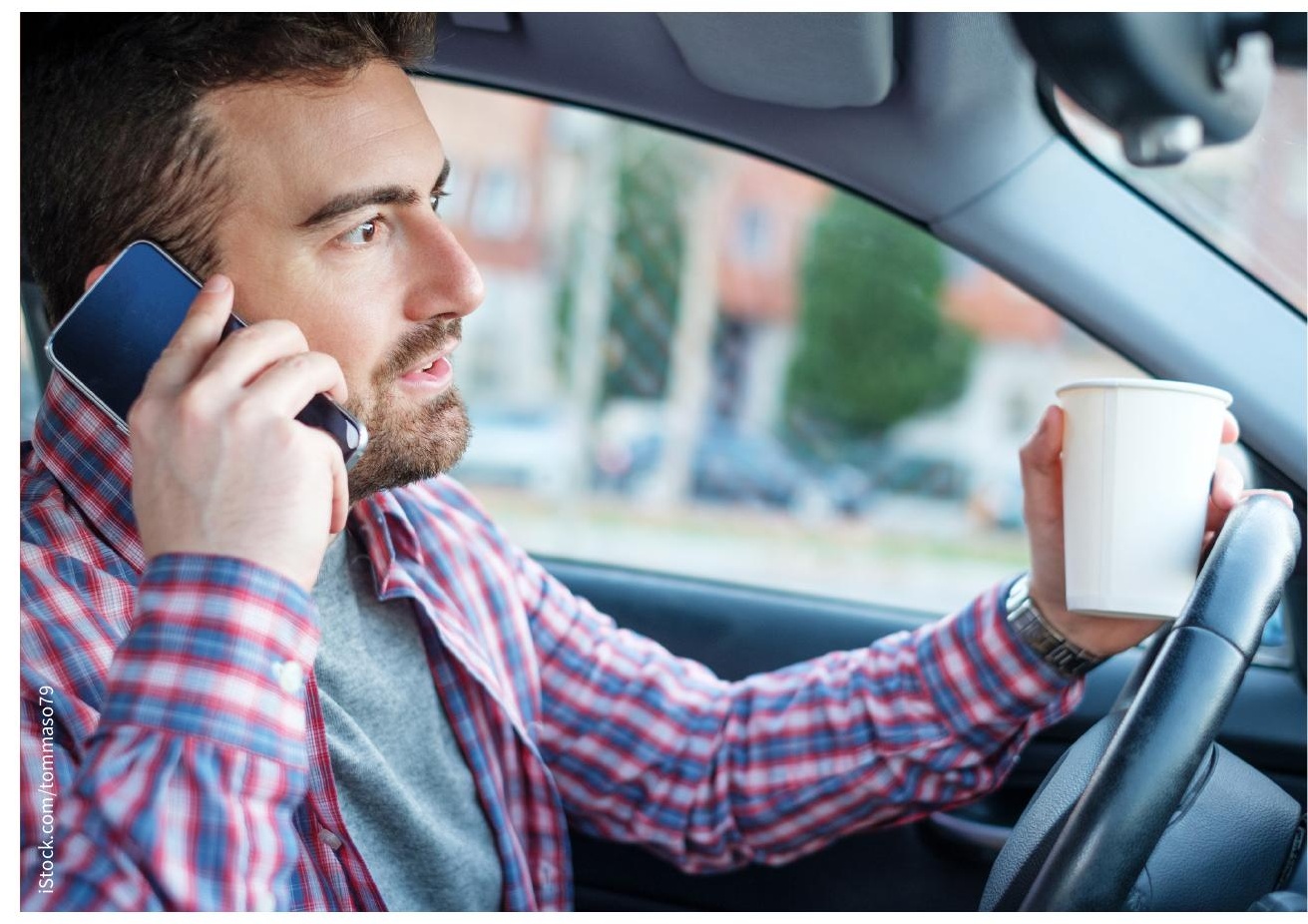

Should there be different rules of engagement for virtual care appointments?

out on that behaviour, which does not respect my professional time, and will remind them that I have other patients to call," Lee says.

For example, if Lee can tell that a patient is driving or getting coffee, he asks them to call back when they can give their undivided attention to the appointment.

Most patients have "common courtesy and common sense," Lee says. But that courtesy goes both ways. Lee schedules buffer time in case he runs behind, although patients occasionally need to wait five to 10 minutes past their call time. "When I have been late to call, they have been extremely understanding," he says.
Heather Thiessen, a patient partner with the Health Standards Organization in Saskatoon, says a renegotiation of how and where health care happens was overdue. "It took a pandemic for us to find new, creative ways to meet patients where they are at, and allow them to decide if they want to go into a visit or if they can do it in the privacy of their home," she says.

Thiessen has heard mostly positive feedback about virtual care, but patients have told her they are worried their doctors will see and judge their messy living conditions during calls.

"It takes working together to find that sweet spot of what works well for everybody," Thiessen says. "Physicians 
can't just decide how they are going to do things. You have to have meaningful conversations with patients and families to establish a new norm and I don't think we have done that."

Sally Bean, director of health ethics alliance and policy at Sunnybrook Health Sciences Centre in Toronto, says there are bound to be growing pains when changing the context of the doctorpatient relationship.

"When you go to your physician's office, it is very much oriented around the caregiver providing care to the patient and they control that," Bean says. "Shifting that locus of control, or taking that away, is definitely going to cause some discomfort."

Bean says doctors should consider what is needed for successful visits and send patients advance recommendations, such as using earbuds or timing the appointment when there will be fewer interruptions. "But you really do have to have flexibility and know that unforeseen, unanticipated things are going to arise for all of us, including the physician," Bean says.
Moira Stewart, a family medicine researcher at Western University in London, Ont., says making a personal connection is key to earning patients' trust and cooperation on new platforms. She recommends starting appointments by acknowledging how the doctor-patient relationship is changing by saying, "This is an unusual way for us to be communicating. It's new to me and it's probably new to you. Let's work on this together."

Abigail Cukier, Hamilton, Ont. 